\title{
COMPROMISO GENERACIONAL DE TERENCI MOIX EN EL LIBRO DE MEMORIAS EXTRAÑO EN EL PARAÍSO
}

\author{
Fermín Domínguez Santana \\ Universidad de La Laguna \\ fdominguez@ull.edu.es
}

\section{RESUMEN}

En la década de los sesenta del siglo xx, el escritor Terenci Moix vivió una serie de acontecimientos que dejó plasmados en su tercer libro de memorias (Extraño en el paraíso, 1998): su estancia de varios ańos en París y Londres, su vuelta a Barcelona y sus periodos en Madrid. En ese volumen toma imágenes de esos ańos para construir un relato íntimo y personal, pero que, en ocasiones, cobra una relevancia colectiva. Este trabajo analiza el discurso del autor catalán en relación con el compromiso con una generación, la suya, que sin duda tomó una actitud combativa frente a los valores propios del franquismo.

Palabras clave: memorias, compromiso generacional, autorrepresentación, memoria colectiva, Terenci Moix.

\section{TERENCI MOIX'S GENERATIONAL COMMITMENT \\ IN EXTRAÑO EN EL PARAÍSO}

\section{Abstract}

In the ninety sixties, Terenci Moix lived through a series of events that he wrote in his third memoir (Extraño en el paraiso, 1998): his stay for several years in Paris and London, his return to Barcelona and his time in Madrid. In the book, he takes images of those years to build an intimate and personal story that, sometimes, takes on a relevance for the collective. This work analyzes the Catalan author's voice in relation to his commitment to his generation, which undoubtedly took a combative attitude towards the values of the Franco regime.

KEYWORDS: memoirs, generational commitment, self-representation, collective memory, Terenci Moix. 
Entonces empecé a comprender lo que ahora he comprendido del todo: que la vida es un regreso constante a lugares que nos contuvieron una vez suprema, estigmatizante, definitiva.

El día que murió Marilyn, Terenci Moix

\section{INTRODUCCIÓN}

Como figura relevante de la literatura catalana y de la literatura en español de los últimos cuarenta años del siglo xx, Terenci Moix (nacido Ramón Moix i Meseguer) fue un escritor catalán que representó una identidad, dentro y fuera del relato novelístico, a todas luces necesaria en una época, la última década del franquismo, de profundos cambios en los planos social y cultural.

Su vivencia individual en la realidad cultural más allá de las fronteras españolas, principalmente en su contacto con la vida de París y Londres, acentuó una mirada crítica, siempre irónica y en ocasiones ácida, hacia una parte de la sociedad española y catalana. Una transgresión de obra y espíritu que agrupa a Moix en la generación de jóvenes que inició una transición cultural en los años sesenta y que preparó el terreno para el cambio que la sociedad española hubo de experimentar tras la transición política, que se ha llegado a calificar como «transición heroica-hedonista» (Ramos 79).

Sin pertenecer de forma plena a ningún grupo, la obra del escritor catalán se alinea en esta intención transgresora con colectividades más o menos consolidadas como la gauche divine o los Novísimos, pero también, aunque quizá en menor medida, con otros movimientos contraculturales de la época ${ }^{1}$.

En lo que respecta a colectivos cuya reivindicación de derechos comenzó a ser muy activa a finales de la década de los sesenta, desde luego, no representó, como activista, un papel relevante para el movimiento gay del momento (Mira, $E l$ niño 186). Aun así, no puede negarse la influencia cultural que los personajes gais de sus novelas (en especial de El dia que murió Marilyn) ejercieron en la consideración pública de «lo homosexual», además de su actividad pública en la vida social española de los años ochenta.

Asimismo, Moix coincidió con otros escritores coetáneos en la palpitante necesidad generacional de romper con una cierta imagen y unos ciertos valores que había representado España y, más concretamente, Cataluña durante su infancia y adolescencia. Su obra comparte, con autores como Juan Marsé, la reivindicación de una juventud que, a finales de la década de los sesenta, se rebeló como literariamente combativa contra las bases ideológicas del franquismo, pero también contra

${ }^{1}$ Entre los que se podrían incluir diversos artistas como el pintor Ocaña o el historietista Nazario. 
una parte de la sociedad catalana, la burguesa, cuyo inoperante beatismo el escritor procuró atacar con aguda ironía.

El análisis de este espíritu combativo, no únicamente presente en su obra, sino también evidenciado en las páginas de sus memorias, publicadas en tres volúmenes bajo el nombre colectivo de El peso de la paja entre 1990 y 1998, permite arrojar luz sobre el deber generacional del escritor hacia sus contemporáneos.

El interés que despierta una figura como la de Moix, «ejemplo de mirada (actitud, identidad, gesticulación) resistente a cualquier identidad externa» (Mira, El niño 186), se sustenta en su difícil catalogación dentro de lo que se ha venido en llamar «literatura gay». Su propia sexualidad, y la presencia de ella en su obra, ha sido objeto de estudio. Por ello, resulta interesante tomar como objeto de análisis el papel que juegan las memorias del autor en la configuración de su identidad y en la caracterización de su compromiso con su generación.

De los tres volúmenes de sus memorias (El cine de los sábados, sobre su infancia; El beso de Peter Pan, sobre su adolescencia; y Extraño en el paraíso, sobre su experiencia como joven adulto) es el tercero el que persigo estudiar en relación con los aspectos antes referidos y con la idea de que, bajo las experiencias relatadas y los pensamientos expuestos por Moix en el texto autobiográfico, se esconden indicios de lo que podríamos dar en llamar compromiso generacional.

Bajo este prisma, la autorrepresentación de Moix y la construcción de su identidad literaria a partir de sus libros de memorias, principalmente en lo que respecta al papel que en esta elaboración juegan el cine y la cultura popular, han sido acertadamente estudiadas por, en primer lugar, Paul Julian Smith, quien analiza El cine de los sábados. Su interpretación, en parte basada en la paradoja y perversidad que Dollimore (citado en Smith) relaciona con la obra de Oscar Wilde, pone el énfasis en que la aparición de esta perspectiva cinematográfica sirve a Moix «to project and to protect an ostentatious, yet fragile, sense of self» (43). De esta manera el cine permite no solo la creación de la propia identidad, sino que sirve de evasión del «black and white world of post-war Barcelona» (44). No obstante, según el crítico, el cine es usado para presentar escenarios que aportan imágenes planas del sujeto (52).

En segundo lugar, Robert R. Ellis percibe como una unidad la identidad del autor, en especial su identidad sexual, y las imágenes del cine que consumió durante su infancia y adolescencia (94). En esta línea, Ellis no concibe en Moix que la sexualidad constituya por sí misma una esencia, sino una mirada que proporciona los mecanismos para desnaturalizar y volver queer las construcciones naturales de la ideología heterosexual (96).

Por su parte, Josep-Anton Fernàndez (25) describe el proceso de construcción identitaria en El dia que va morir Marilyn (1969), es decir, la interpretación que los protagonistas hacen de sus experiencias a partir de imágenes cinematográficas. Procedimiento que Vilaseca (97) apunta que Moix aplica a sus propias memorias y que, según Alberto Mira (De Sodoma 340), permite la catalogación de sentimientos, de manera que las imágenes del cine nutren de imágenes el deseo.

Por último, David Vilaseca se aleja de las interpretaciones anteriores para afirmar que, en El peso de la paja, Moix articula una aplicación de lo virtual deleuziano. Así, «all the world's phenomena (including himself qua constituted indivi- 
dual) are but an endless replication of 'simulacra'» (98). De esta manera, las imágenes del cine y la cultura popular, como elementos que parten de la memoria, permiten generar potencialidades que trascienden hasta el presente.

En este punto, el uso de imágenes cinematográficas y de la cultura popular, pero también, en consecuencia, de imágenes de la memoria, posibilita la reinterpretación identitaria del sujeto narrativo. De esta manera, las múltiples potencialidades teorizadas por Vilaseca van a proyectar una autorrepresentación distinguida por la ambigüedad identificativa. Así, Moix entabla un diálogo multidireccional que hace que se cuestione continuamente. Esta ambigüedad identitaria, que trataré de analizar en los apartados siguientes, muestra a un autor al mismo tiempo narcisista y camarada. Al mismo tiempo comprometido con una experiencia colectiva (de la generación de posguerra) pero también ajeno al compromiso político.

\section{LA MIRADA DESDE EL EXTERIOR: ENFANT TERRIBLE Y ESTÉTICA CAMP}

Desde su irrupción en la vida social y cultural española, la figura pública de Terenci Moix siempre estuvo asociada a la imagen de enfant terrible. El propio autor reconoce haber perseguido esa intención cuando afirma que

el personaje Terenci pululaba por la vida pública con un peso específico que habría asombrado al Ramón de Plaxtol, pese a que fue él quien lo inventó [...]. Enlazaba con otra figura en la que trabajé a conciencia: la del joven furioso y su variante más tópica: el enfant terrible. Alguna fuerza de veracidad tendría esta imagen porque me ha seguido acompañando hasta muchos años después (Moix 472).

La cita anterior manifiesta el empeño del autor por ofrecer esta doble imagen que se asocia al concepto y que algunos críticos relacionan con su «descaro pop y homosexual» (Gracia y Ródenas 209). Por un lado, la de joven brillante y de ingenio precoz; por otro, la de joven transgresor, cuya actitud y obra se aleja de la ortodoxia.

En buena medida esta imagen viene dada por la identificación del estilo de Moix con la estética camp. Varios han sido los autores que han trabajado esta línea en su análisis de diferentes obras del escritor catalán.

Según Ramos, «la perspectiva de Terenci Moix está más cerca de la que propuso Susan Sontag en su artículo sobre el camp» (85) y reproduce una cita de su conocidísimo "Notes on Camp» (1964) en la que la escritora neoyorquina afirma que la estética camp representa la victoria del estilo sobre el contenido, de la estética sobre la moral y de la ironía sobre la tragedia.

Asimismo, Smith, parafraseando a Dollimore en su análisis de Oscar Wilde, caracteriza la estética de Moix de la siguiente manera: «depth gives way to surface, essence to difference, authenticity to style» (43).

Por su parte, en su imprescindible monografía sobre la historia cultural de la homosexualidad en España, De Sodoma a Chueca, Mira dedica un capítulo a delimitar las características que la tradición gay proporciona a un concepto que el propio 
autor reconoce como «un término difícil, precisamente porque no se refiere a contenidos concretos, sino al modo irónico en que se utilizan estos contenidos» (145). De esta manera, el experto prosigue aseverando la asociación que se hace entre lo camp y los posicionamientos homosexuales y cómo este concepto surge, en buena medida, del reciclaje de manifestaciones del arte popular. Dada la dificultad de traducción del término de la tradición anglosajona, Mira decide mantener la expresión para referirse a demostraciones culturales, mientras que prefiere usar "pluma» para manifestaciones individuales y se reafirma en plantear ambos términos como herramientas subculturales, obviando su consideración homófoba. Bajo este razonamiento «lo relevante es que la mirada gay funciona como anfitriona del encuentro [entre lo kitsch y la parodia]: desde la mirada gay se activa la parodia, la mirada gay reconoce el exceso kitsch $»^{2}(147)$. De los diferentes acercamientos descriptivos que se hacen en este estudio sobre los conceptos planteados, es preciso destacar el que se realiza a través de las palabras del poeta Jaime Gil de Biedma, que llevan a concretar una visión ciertamente política del término camp:

el exceso, lingüístico y de contenidos, sirve para centrar la atención del lector en el lenguaje como parodia; los aspectos lúdicos (en especial la provocación) que enfatizan lo performativo; se construye una mirada a través de lo intertextual y se busca una complicidad con el público gay. $\mathrm{El}$ "fondo» pasa a segundo plano: lo que importa no es lo que el artista trata de decir, sino su relación con el sistema de representación (149).

Este sistema de representación en Terenci Moix es, entre otros ${ }^{3}$, especialmente, el cine y, en palabras de Mira (339), su relación con el deseo ${ }^{4}$. Como herramienta camp, el séptimo arte le permite clasificar su deseo y enfrentarse al mundo desde una interpretación ciertamente esnob; pero, ya que lo hace aún en su adolescencia, esto se produce desde la indefinición y, puesto que el discurso de las generaciones previas no era válido para su visión de la sexualidad, desde la búsqueda de un discurso:

Todo jovencito anómalo tiene que acostumbrarse a buscar sus raíces, y la sobada incógnita de qué fue primero, el huevo o la gallina, nunca es invocada en vano. En el caso del adolescente soñador que yo era, justo es preguntarse si fueron primero los actores o su máscara, si los actores me seducían por su prestancia, la de sus personajes o la carga que yo depositaba en ellos. Sentí transportes amorosos sin reconocer que detrás de este sentimiento pudiese existir una inclinación culpable;

2 En una explicación muy breve y a todas luces incompleta, lo camp estaría caracterizado por el uso irónico de determinados elementos de la cultura popular, una sensibilidad que frivoliza lo serio. Frente a ello, lo kitsch representa el gusto vulgar por producciones culturales de masas que copian la ostentación de las nuevas clases adineradas.

${ }^{3}$ Novelas, ensayos, obras teatrales y operísticas, cómics y diferentes estilos musicales.

${ }^{4}$ El experto hace esta afirmación en su análisis del segundo volumen de memorias de Moix: El beso de Peter Pan. 
en este proceso de idealismo desproveía a mis actores de todo efecto erótico, que descargaba en otros menos queridos o, a partir de un momento determinado, en los adonis de las revistas de culturismo. Desvié hacia aquellos cuerpos desnudos la burda carga del deseo. Era como si no quisiera mancillar a mis galanes, y esta maniobra de ocultación me hace pensar que tenía una clara conciencia del pecado, aunque la disfrazase bajo la aureola de menefreguismo que mi tranquilidad espiritual necesitaba (Moix, citado en Mira 341).

Se añade a lo anterior la visión de Gracia y Ródenas, quienes no solo inciden en esta idea de que la totalidad de la obra de Moix se enmarca dentro de la estética camp (y que ello comporta el uso de cómics, subliteratura, cine clásico y moderno como elementos de la narración), sino que el relato de las aventuras sexuales debe entenderse como una forma de realización personal (697) que, ciertamente, llega a trascender el medio escrito y ofrece una imagen pública del escritor determinada, de alguna manera, por «la provocación y la extroversión un tanto histriónica», citando "programas televisivos donde ejerció de homosexual jovial y burlón, ingenioso, insolente, queer y vedette» ${ }^{5}$ (698) durante la década de los ochenta del siglo xx. En esta imagen también incide Mira, aunque la interpreta en términos de transgresión de los estrictos estereotipos masculinos de los setenta: «Finalmente, se creó la imagen de alguien provocador que incluía sin tapujos la provocación sexual. En un imaginario en que la masculinidad se entendía a partir de estereotipos fuertemente patriarcales, resulta un caso notable» (El niño 187).

La cita de Gracia y Ródenas y la apelación irónica de Moix al término vedette permiten interpretar la actividad pública de Moix, principalmente sus intervenciones en la televisión y en los encuentros de la sociedad española, por un lado, y de forma evidente, como una revelación pública de su identidad; por otro, la visibilización de un hombre joven culto homosexual, alejado de la imagen marginal y clandestina derivada de la aplicación de las leyes franquistas. Obviamente, no cabría la afirmación de que esta visibilidad tuviera, por parte del autor, un consciente interés comprometido con la colectividad, pero tampoco debe obviarse que su presencia en la vida pública española permitía presentar una figura referente, respetada y reconocida en su actividad literaria y cultural.

Estos elementos (el ejercicio de una estética camp, la vida pública de Moix y el desarrollo de la imagen de enfant terrible) se podrían entender entonces como herramientas que permiten que el autor en su autobiografía "offers insight into the interconnectedness of popular culture and gay self-representation, positing gay sexuality not as an essence but as a gaze through which the ostensibly natural constructions of heterosexual ideology are denaturalized and rendered queer» (Ellis 91). Por lo que Moix, a través de esta mirada que trasciende y difumina los límites entre masculino

${ }^{5}$ Moix ironiza sobre este apelativo en Extraño en el paraíso: «congregó a tal número de personalidades que el corresponsal de La Vanguardia tuvo que titular su crónica «Terenci, vedette en Madrid». Y aunque tal afirmación pueda parecer frívola, respondía a una realidad más valiosa aún que el éxito» (505). 
y femenino, estaría posibilitando consecuencias beneficiosas para la colectividad sin consciencia siquiera de tal efecto, como he afirmado más arriba.

Junto con la interpretación a partir de la estética camp, otros autores explican ciertos elementos de la obra de Terenci Moix desde la óptica de la posmodernidad. De esta manera entiende Ramos

la disolución de las fronteras entre lo popular y lo "culto», la creación de su personaje público, la mirada irónica hacia el cine y la canción popular como estrategia de subversión del discurso dominante, la convivencia en su escritura de registros marcadamente diferentes o la defensa del mestizaje y de las sensibilidades marginadas (82).

En términos parecidos se expresan Gracia y Ródenas cuando afirman que la egiptología, de la que Moix era gran conocedor y que está presente en algunas obras del escritor catalán, se presenta a través de una estudiada frivolidad, aunque con una documentación importante. Esto constituye, según los críticos, un gesto posmoderno (254). No es descabellado afirmar que ciertas propiedades que se suelen asociar con lo posmoderno están presentes en la creación narrativa de Moix. Así lo aparentan aspectos como el empleo de la recursividad del relato o la parodia, pero también cierto apego por el hedonismo y la consideración de las manifestaciones artísticas que se interpretan como cultura de masas.

Sin embargo, cabría recordar que escritoras como Susan Sontag, quien procuró en sus ensayos un primer acercamiento al concepto camp, no aceptaron estimar la posmodernidad como un movimiento estético propio, sino que lo entendieron como una extensión, más comercial, de la propia modernidad (Soler).

\section{CONSTRUCCIÓN Y DISCUSIÓN IDENTITARIAS}

A propósito del primer volumen de las memorias de Moix, Alberto Mira realiza una profunda caracterización queer del niño pregay presente en $E l$ peso de la paja. Según Mira, tres enfoques permiten caracterizar los años de infancia del autor catalán. En primer lugar, la dinámica identitaria, es decir, las «ideas y lugares comunes» (El niño 189) que se utilizan para representar al niño queer. En segundo lugar, la dinámica del deseo, que permite al Terenci adulto explicarse a través de la inclusión de pasajes homoeróticos en su infancia. Por último, la dinámica de socialización homosexual, ya que las memorias de Moix transmiten una idea de comunidad, de colectividad. Esta última dinámica permite a Mira apuntar que, pese a que en absoluto debe considerarse a Terenci Moix como un referente o un miembro activo del «movimiento homosexual», en las páginas de las memorias se atisba cierta idea de comunidad.

Por su parte, Alfredo Martínez Expósito no solo apunta al origen moderno y metafórico del término homosexual (Los escribas) sino que, partiendo del concepto ostranenie de Víktor Shklovski, que entiende que «el propósito del arte es el de impartir la sensación de las cosas como son percibidas y no como son sabidas» 
(citado en Martínez Expósito, Normalización 29), deduce la capacidad de la literatura de crear paradigmas alternativos que "han ayudado a ciertos lectores a sentirse un poco menos extraños; [...] la normalización literaria [...] sentó los precedentes para otras normalizaciones de la experiencia homosexual que vendrían más tarde» (29). El crítico otorga a la escritura autobiográfica de los ochenta (periodo anterior a las memorias de Moix) un carácter combativo y militante con dos efectos: dar voz y normalizar la experiencia homosexual sobre el discurso heterosexual. Con esta breve tradición aparecen los textos memorísticos de Moix en la década de los noventa, en la que, según Martínez Expósito, los textos buscan la colectividad, aspecto que podemos entender subyacente en las memorias del autor catalán y que toca con el aspecto humorístico de muchas obras del momento sobre "lo homosexual», que en Moix se traduce en el uso de la parodia y cuyos efectos son la cancelación del sentido crítico y el potencial subversivo (35), ya que el empleo de personajes homosexuales genera consecuencias de desestabilización social (Los escribas 34).

Siguiendo a Mira (El niño), el crítico realiza una caracterización del concepto «homosexual», con la vigencia que tenía en los años noventa, cuando las memorias fueron escritas, y las semejanzas entre los rasgos atribuidos al término entonces y las cualidades que se extraen del niño Ramón en las páginas de El cine de los sábados. De esta manera, apunta a singularidades como "afeminamiento, gusto artístico, decadencia, neurosis, matrocentrismo, perversión, descaro, exhibicionismo, narcicismo...» (192).

Sobre estas cualidades, resultan imprescindibles los trabajos de Oscar Guasch. En el primero de ellos, el ensayo La sociedad rosa, el más cercano temporalmente a la redacción de las memorias, el antropólogo hace un primer acercamiento a la creación de la subcultura gay, que ha completado más recientemente. Guasch diferencia tres estereotipos: 1) el asociado a la etapa pregay (periodo franquista), caracterizado como el gay afeminado (marica) y el gay de comportamiento semejante a varón heterosexual (maricón) (13); 2) la etapa gay (entre 1975 y 1992), en la que se produce una masculinización del estereotipo por influencia del modelo gay anglosajón; y la 3) hipergay (desde los años noventa), en la que surge un estereotipo hiperviril (15).

Por lo que respecta al tercer tomo de las memorias, el análisis autobiográfico que hace Moix de su propia identidad en Extraño en el paraíso permite apreciar cómo una parte de estos rasgos siguen presentes en el joven Ramón Moix, pero, a ratos, aparecen reformulados o cuestionados, lo que da una idea de que durante los sesenta el joven de veinte años, en su «salida al mundo», repiensa algunos aspectos que había mantenido vigentes hasta ese momento, o bien el Terenci de los noventa quiere imprimir en sus recuerdos del acceso a la edad adulta esta suerte de ambigüedad que, por un lado, mantiene ciertas singularidades del nińo-adolescente-Ramón, y por otro quiere cuestionar su compromiso político con la urgente renovación social que la juventud española de la última década del franquismo venía demandando.

La primera vertiente mantiene la prevalencia de las propiedades del término «homosexual» planteadas por Mira en su análisis de El cine de los sábados. De esta manera, está presente durante todo el tercer tomo un gusto por cualquier repre- 
sentación artística, ya sea en forma novelística, gráfica, audiovisual, teatral o musical. En esta línea, el "gusto por lo artístico» llega a representar su propia identidad:

Chelsea, donde era posible presentir que Ramón Moix sería un extraño conglomerado de melodías, pinturas, esculturas, obras teatrales, modas, ismos, períodos, visiones y augurios [...] Viví de su ritmo durante muchos años [...] cuando pude ser Terenci por el solo hecho de remitirme constantemente a ese origen (Moix 295).

Y como elemento fundamental de la caracterización de la identidad se superpone al mismo desempeño de la sexualidad, como ocurre durante la relación no física con Stephen durante su estancia en Inglaterra.

De la misma manera, la «decadencia» se muestra en las páginas del volumen en multitud de ocasiones: en la convivencia de la comuna de tumbleweeds de la librería Shakespeare and Company del quinto distrito de París y en el piso compartido por numerosos migrantes en Chelsea, mientras Ramón y Carlitos trabajan fregando platos en la cocina de un restaurante.

Asimismo, la «neurosis» concurre durante la obsesión amorosa por Daniel y el «matrocentrismo» se revela durante varios momentos del relato: en la breve estancia en la vivienda familiar de Barcelona tras el regreso de París, durante la que Ramón llega a recurrir a buscar "desesperadamente a mi alrededor la ayuda de mamaíta» (230); y en la figura de Lettie, la amiga londinense, con posterioridad.

En relación con los atributos de "perversión» y «exhibicionismo», Smith afirma que

Moix's 'perverse dynamic' does not operate outside that heterosexual culture whose norms it tends to subvert, but is rather wholly contained by that dominant culture. In spite of his frequent allusions to an international 'gay sensibility', for Moix homosexual identity is problematic indeed. Like Goytisolo before him, he refuses to admit the existence of a communality of experience based on (homosexual) desire, because he recognizes that that desire is itself culturally constructed (43).

Lo que se traduce -en las múltiples concurrencias de secuencias Extraño en el paraíso en las que la sexualidad cobra protagonismo-, en que esta permite, al tiempo, la autoafirmación y la rebeldía (Ramos 82) pero, precisamente por ello, acrecienta la aparición de actitudes narcisistas ${ }^{6}$ que no solo explicita Ramón: «yo seguía siendo el niño egoísta, centralizador del mundo, usurpador exclusivo de todos los derechos de la existencia» (Moix 474), sino que también se manifiestan a través de lo que dicen otros personajes, como la afirmación de Lettie, la amiga londinense, tras la ruptura definitiva con Stephen: «tú eres un monstruo del egoísmo. Todos los que te rodeamos estamos hasta el cońo de tu maldito aprendizaje [...]. Francamente,

${ }^{6}$ Otro ejemplo que incide en este narcisismo ocurre en El cine de los sábados. Durante un viaje a Italia, su amigo Pasolini le dice «Tú no tienes sexo. Entre las piernas sólo te cuelga una filmoteca» (37), ante el desinterés de Moix por el sexo y su deleite intelectual. 
la gente merecemos algo más que un crío inmaduro que sólo reacciona cuando ya no hay nada que hacer» (457).

Pero si algo caracteriza identitariamente al joven Moix en el tercer volumen de sus memorias es el cuestionamiento de los principios que habían regido su vida durante la infancia y la adolescencia. Los veinte años suponen para él el comienzo de una época en la que explorará el mundo más allá del entorno de su familia y de su barrio, ya que se muda a un piso en Barcelona que comparte con una pareja neozelandesa. Pero también el mundo más allá de la gris y beata España de su infancia. Sus temporadas en París y Londres van a comportar una cierta ruptura con su yo más desentendido de la realidad que le rodea. Esto, por supuesto, ocurre no solo desde un punto de vista sexual, ya desde el principio de la obra afirma: «Nací a los sesenta asumiendo que el amor entre hombres es una bendición y no el nefando delito que castiga la religión de los curas» (Moix 10), sino que se extiende a la valoración que hace de su propio recorrido vital. Y, por tanto, a la valoración de su recorrido literario hasta ese momento, particularmente después de su experiencia inglesa: «En un extremo estaba el joven aprendiz de perverso que se complacía retorciendo fantasías turbulentas [...]. En otro extremo, pugnaba el joven concienciado que, desde hacía tiempo, quería adscribirse a las tendencias más progresistas de su tiempo» (Moix 472).

Y también:

¿A qué estoy jugando? A todo menos a la sinceridad. No puedo permitirme el lujo de seguir interpretando a una especie de nińo prodigio que para sorprender al mundo sólo cuenta con las armas de la precocidad y el descaro. Esto resultaba gracioso cuando tenía diecisiete años, pero ahora tengo veintidós y he de decidirme a buscar intereses más sólidos... (472-473).

Estas diatribas del escritor que, hay que ser conscientes, realiza el Terenci de los años noventa, guardan relación, no obstante, con la publicación en esos años de la novela El día que murió Marilyn (1969), que, en palabras del propio escritor, «tenía, pues, muy claro que mi novela debía convertirse en el manifiesto de una generación de jóvenes españoles, pero esta idea no podía excluir otros temas mayores» (474). Esta valoración del carácter generacional de la novela es realizada por Moix en sus memorias veinte años después de la publicación de la narración. Bajo mi interpretación, el autor juzga en Extraño en el paraíso la significancia del compromiso generacional de su novela, de la misma manera que juzga su falta de interés por los movimientos políticos de los setenta. Esto forma parte del diálogo multidireccional que el autor lleva a cabo en sus memorias y no solo pone de manifiesto la ambigüedad que se ha sugerido, sino que ejemplifica las múltiples potencialidades del simulacro narrativo.

Sobre la relación entre esta novela y los volúmenes de las memorias, Mira afirma que

la construcción de una identidad homosexual basada en la apropiación camp son comunes a ambos textos, así como las dudas sobre la asunción de esta identidad, el rechazo hacia otros homosexuales y la idea de la asunción de una identidad 
homosexual a la vez como don y como condena eran también temas recurrentes (De Sodoma 384).

A pesar de esta visión de reformulación identitaria que realiza el autor en sus memorias, una parte de la crítica reafirma su figura desentendida de la realidad sociopolítica de la década: «Terenci Moix encarnó entre 1968 y 1969 una forma insospechada de precocidad irritantemente narcisista, caprichoso y vivacísimo narrador» (Gracia y Ródenas 698). Los críticos fundamentan su afirmación en que, con respecto a los dos primeros volúmenes de las memorias, en Extraño en el paraíso se muestra un Ramón influido por la figura de Pasolini en Italia y por la de Néstor Almendros en París, que se ha empapado tanto de literatura y cine, como de la práctica sexual libre en Chelsea y el acercamiento a contactos literarios en el local Oliver de Madrid (722). Precisamente en estas conexiones personales se genera la conciencia de colectividad y su tratamiento en los textos memorísticos permite la multiplicidad de potencialidades, cuya influencia en la identidad del escritor propicia un alejamiento de su única interpretación desde el par activismo político / oficio literario.

Este cuestionamiento identitario se establece en el contenido de las novelas y libros de memorias, pero también puede rastrearse hasta en el propio uso de la lengua catalana o espańola. En este sentido, aunque Ramos, citando a Josep Maria Castellet, menciona que el paso de Moix del catalán al espańol responde a fines comerciales (83), parece más acertada la interpretación de Smith, quien (44) se inclina por dar una respuesta psicológica a la decisión de Moix de escribir en una u otra lengua cuando manifiesta que el autor se aleja de la influencia lingüística de su padre, cuya lengua materna es el catalán, para significar su rechazo a la opresión que su figura representa. Esto es lo que le llevaría a escribir sus novelas más tardías y sus memorias en español, además del hecho de que sus referentes (cinematográficos) también los asimila durante la infancia y la adolescencia en esta lengua. Sumado a lo anterior, el propio autor aporta una plausible explicación que, por otra parte, comparte con otros escritores catalanes que recibieron su educación primaria durante el franquismo. Es decir, que su formación escolar se realizó en español por imperativo de las circunstancias políticas del país. Así lo manifiesta Moix en una entrevista en la Universidad de Granada en 1996 al explicar las razones que le llevaron a reelaborar la novela El día que murió Marilyn:

Para mí existía ese problema básico que era el de un idioma no dominado por mí y además muy coartado por las circunstancias [...]. Era un idioma que salía de muchos años de prohibición, que no se nos enseńaba en la escuela. Es decir, yo tenía cuatro premios literarios en catalán y todavía estaba asistiendo a clases de catalán en la clandestinidad (Facultad de Filosofía y Letras minuto 7:30).

Siguiendo este hilo, pese a la evidencia de que la figura de Moix en la literatura catalana gozaba de un papel más relevante que en la española en el momento de la redacción de sus textos memorísticos, la interpretación que da el autor sobre la elección del espańol coincide en parte con la dada en múltiples ocasiones por otro escritor catalán de parecida experiencia. Así, en su discurso de aceptación del Premio 
Cervantes de 2008, Juan Marsé (RTVE minutos 15:45-17:25) incide en que esta elección en su caso, y que hago extensible a Moix, no únicamente viene derivada de la situación clandestina que padeció la lengua catalana durante el franquismo, sino, sobre todo, de que su formación como escritor, es decir, la adquisición de mecanismos narrativos, se produjo a partir de las lecturas (cuentos, novelas breves, cómics, etc.), pero también de las películas, que consumieron durante su infancia y adolescencia. Y, por supuesto, la asimilación de estos mecanismos se produjo en su asociación con la lengua española, ya que, por razones políticas, no existía otra posibilidad de llegar a estos productos culturales.

Pero el proceso que lleva a escribir en una lengua comporta una cuestión sentimental (en palabras de Marsé) lo suficientemente compleja como para no caer en el error de intentar reducirla en exclusiva al mayor rédito económico de una obra literaria o a un dominio mayor de estructuras lingüísticas. No obstante, aunque se trata de un proceso personal que experimenta cada autor, resulta evidente que ello tiene su efecto en la autorrepresentación identitaria. En este sentido, Moix verbaliza en la entrevista citada que, en su caso, consideró necesario realizar una revisión de El dia que va morir Marilyn, que se publicó en 1996, porque tenía carencias narrativas y de registro lingüístico. Aspectos que no afectaban a la versión en español de la novela.

Al igual que ocurre con otros escritores que toman imágenes de la memoria individual para formalizar los argumentos narrativos de sus escritos, los límites entre realidad y ficción, es decir, entre el recuerdo rememorado y la construcción narrativa, son difusos. En el caso de Moix la anterior afirmación no solo se aplica a novelas como El día que murió Marilyn (1970), sino, de igual manera, a sus libros de memorias, a los que el propio autor reconoce su carácter literario cuando afirma: «No me hubiera costado nada hacer una confesión y basta, pero el libro [El beso de Peter Pan] tiene precisamente la estructura que me es propia, la de novela» (Moret).

Y esto ocurre así porque el proceso genésico que opera en la obra de Moix, y por el que dialoga con su identidad en Extraño en el paraiso, es el que también ha sido descrito para autores contemporáneos como Juan Marsé. Según este proceso, el autor toma imágenes de su memoria individual que manipula para dotar de verosimilitud narrativa al relato (Domínguez 237). De manera que esta caracterización identitaria se produce desde el presente hacia el pasado, es evidente que en el texto autobiográfico el autor proyecta hacia el pasado una cierta imagen suya o unos atributos específicos que significa frente a otros, pero lo que también está claro es que esa proyección crea una serie de imágenes en ambas direcciones con efectos en la identidad del escritor.

\section{TERENCI MOIX Y SU COMPROMISO GENERACIONAL}

Ya mencionamos más arriba que el proceso narrativo de Moix, quien se vale de imágenes de su memoria individual en la elaboración del relato, se asemeja al de otros autores del mismo periodo, a quienes influye de manera notable su contacto con el cine en una época (década de 1950) en que este se convierte en medio 
de masas. Ahora bien, cabe analizar en qué medida la manipulación que se hace de estas imágenes de la memoria individual para incluirlas de forma verosímil en el continuum narrativo de los libros de memorias puede entenderse, en cierta medida, dentro de lo que se viene en llamar memoria colectiva de la generación.

En su artículo sobre El cine de los sábados, Alberto Mira apunta al concepto "comunidad" para significar la relación de Moix con su generación. Aunque reafirma que el escritor catalán «en sus pequeños gestos de afirmación y rechazo, tampoco pareció demasiado interesado en las luchas que el movimiento llevó a cabo desde finales de los setenta» (El niño 201), es decir, que Moix rehúsa significarse activamente con las luchas del movimiento gay, Mira ubica al escritor en la órbita de la interacción colectiva de la comunidad gay, no únicamente en lo que el crítico denomina socialización homosexual a través de encuentros sexuales, sino, y muy especialmente, a través de prácticas culturales. Pero, como ya hemos visto en apartados anteriores, el activismo político consciente no es la tesis principal que defiende este compromiso generacional. En este sentido, según Mira, el círculo de amigos del tío Cornelio, en este primer volumen de El peso de la paja, tiende a considerarse como un espacio de identificación del Terenci niño, de manera que el tío Cornelio se erige como una especie de modelo, que, pese a ciertos rasgos negativos ya anteriormente referidos que se asocian al concepto "homosexual» de la época (cursilería, narcisismo, etc.), se presenta con una imagen de respetabilidad y estabilidad.

Esta relación de Moix con la comunidad, que se ejemplifica en los párrafos siguientes y cuyo principal fin es la búsqueda de modelos identitarios, sigue presente en Extraño en el paraiso, donde el escritor se inicia al exterior tras abandonar el mundo adolescente y emprender la experimentación de otros ambientes y sociedades con su «emancipación» en un pequeño piso de Barcelona y, posteriormente, con su autoexilio en París y en Londres.

En el caso de la socialización homosexual propuesta por Mira y la relación del escritor con la comunidad gay, es posible establecer una diferencia, en el tercer volumen de las memorias, entre, por un lado, las prácticas culturales, que permiten a Moix mostrar bajo su óptica los encuentros sociales de una parte de la comunidad gay de los sesenta, y, por otro lado, los encuentros amoroso-sexuales, que son tratados desde un prisma muy diferente.

En los encuentros sociales de la comunidad la nota predominante es la de presentar a los miembros del grupo a través de esa imagen de «homosexualidad» de la época, que actualmente se entendería como particularmente homofóbica:

Esas locas egregias a las que el joven herético ha ido conociendo en los bares, llevan en su combate por la supervivencia nombre de guerra que denotan la inventiva del gremio en épocas de represión. [...] Recuérdese a la Sotracs (es decir, la Sobresaltos), un cuarentón así llamado porque cierto día, intentando meter mano a un casado en la general de un cine de reestreno, éste le empujó con tan malos modos que le hizo caer al patio de butacas. [...] Así, a un tal Albert le llamaban la Tecla, sólo porque era profesor de piano. A Felipín, jefe de empresa, la Rebeca de Winer, porque siempre se presentaba con esa prenda, discreta a la par que elegante. A Ramiro, ejecutivo, la Jane Eyre, porque de tan serio parecía una institutriz. A Gonzalo, la Alice Faye, por los carrillos hinchados. A un profesor de latín, la Calpurnia Graco. 
$Y$, en fin, a tres reputados directores de teatro de vanguardia dieron en llamarlos las Gradulux porque los tres llevaban gafas (15-16).

Estas caracterizaciones a través de un apodo ridiculizante y claramente irónico (Fone, Ironía) evidencian uno de esos atributos (cursilería) del concepto trasnochado de «homosexual» y aparecen de forma concurrente en otros momentos del volumen. Así ocurre tras la presentación de la pareja de neozelandeses, compañeros de piso: «Ellos enseñan al joven herético que toda maricuela que se precie de cosmopolita encuentra en el exhibicionismo una forma de realización erótica tanto o más satisfactoria que en el coito» (17).

La tónica común a estos rasgos negativos de la homosexualidad es su manifestación asociados a la generación anterior de la comunidad ${ }^{7}$, que Moix nominaliza como «las supremas locazas» (16) y que representa a los miembros del colectivo nacidos en la década de 1920 o antes y que, en 1962, superaban los cuarenta años: «mariquitas feúchas, de esas que, a falta de oportunidades de cama, tenían la virtud de alegrar la noche a los demás a base de imitaciones desmadradas» (49). El joven Ramón Moix asiste a estas reuniones más como espectador que como participante y esto permite plantear un primer elemento de diferenciación con respecto a la generación de los que, en los años sesenta, superan los cuarenta años. Al contrario que la generación anterior, el grupo de personajes coetáneos a Moix participa de estos eventos como divertimento excéntrico (así ocurre, por ejemplo, en el caso de Jaime Gil de Biedma o Néstor Almendros en Barcelona) o para el desahogo sexual (en el caso de Carlitos en Chelsea). Este distanciamiento con respecto a la generación anterior no se genera porque Moix ignore el contexto histórico de sus mayores. Si seguimos a Guasch (La construcción), tanto el autor como sus mayores estarían encuadrados vivencialmente en el estereotipo pregay, pese a que el catalán no vivió, de forma consciente, la posguerra inmediata. Por el contrario, esta diferenciación bien se revela en la siguiente cita de Extraño: «[Stephen] Correspondía, en cualquier caso, a mi idea del homosexual maduro que se proyecta en el más joven en calidad de educando; idea que, sin yo presentirlo entonces llegaría a aplicar a mi vez» (447). La primera divergencia viene dada por el propio uso de los términos. Por un lado, Stephen es un «homosexual maduro"; por otro, los otros mayores son, como ya se ha visto, «supremas locazas» o "mariquitas feúchas». De una parte, en los fragmentos en los que aparece Stephen (al igual que ocurre con Gil de Biedma y Pere Gimferrer $^{8}$ [552], pero también con Juan Marsé [548] y Manuel Vázquez Montalbán [549]) Moix no aplica la mirada camp; en cambio, sí lo hace en el caso del grupo de las reuniones mencionadas en párrafos anteriores. El eje que vertebra esta diferencia es que Moix no considera modelos identitarios al segundo grupo, frente al primero, ya sea porque son homosexuales mayores o escritores. La razón de esto es que, en

7 El autor los aplica a la generación mayor, pero de la misma manera los emplea en su estética, ya que, en gran medida, son parte de la mirada camp.

${ }^{8}$ Incluyo en este paréntesis personas de la misma generación de Moix, incluso más jóvenes, además de heterosexuales, porque mi intención es estirar un poco más la deducción. 
la búsqueda de modelos de Moix, como ya se ha visto anteriormente, pesa más el aspecto intelectual que el sexual y, en relación con los nombres puestos de ejemplo en las líneas superiores y, en palabras de Stephen: «nos hermana la voluntad de preservar la belleza por encima de los desmanes de la época» (447).

El cuestionamiento de las generaciones pasadas no solo se circunscribe al ámbito del colectivo gay, sino que, de forma transversal, comprende a los padres, a los que se recrimina su sobreprotección, que es entendida como limitación de la libertad personal:

El niño de veinte años se fue del Peso de la Paja con esa facilidad que teníamos entonces para dejar en casa las cosas que ya no servían de cara al futuro, siendo las primeras los mandamientos de la ley de Dios y el manual de urbanidad. Me hallaba en esa edad divina en que la profesión más deseable es la de respondón, y todos los oficios que los padres han elegido se nos antojan una insoportable rémora del pasado. Oficios y beneficios, quiero decir. Y también bendiciones, bondades, dádivas. Nada de cuanto ellos pudieron planear nos sirve, ninguno de sus intereses nos interesa, todo cuanto hacen para conseguir nuestra complicidad repercute en un efecto contrario. Su sola presencia nos enajena, sus comentarios nos llevan a ser respondones, sus opiniones generan al punto una opinión contraria que puede llegar a gritos y acompañada de tacos. Y ese descaro es la máxima expresión del deseo de libertad (Moix 15).

Esta tensión generacional ha sido estudiada por Ramos a propósito de la relación de Bruno y Jordi con sus padres en El día que murió Marilyn (91-95), novela que representa un intento de alejarse del estereotipo de homosexual de la época: «criminal, corruptor, perverso, degenerado, enfermo, afeminado, promiscuo» (Mira, De Sodoma 376) y en la que, al igual que Ramón Moix en Extraño en el paraíso (227240), sus personajes reniegan de convertirse en los herederos del negocio familiar y seguir los pasos paternos dentro de la pequeña burguesía (91).

Junto con esta negativa a seguir el legado familiar, posiblemente el elemento que más acerca a Moix a otros escritores de su generación es la inculpación que los jóvenes de la novela hacen a sus progenitores de haber aceptado sin más las imposiciones del franquismo (Ramos 92) y la reacción contraria a estas ideas que tiene la generación del escritor catalán: «yo tendía a expresar mi repugnancia por el pasado que me había sido impuesto» (Moix 437).

Y esto es así porque Moix y los escritores de su tiempo pertenecen a esa

mitad de la población espańola [que] a la altura de 1965 carecía de experiencia de guerra y eran víctimas puras de la posguerra. Habían crecido ahí pero su edad adulta coincidía con las primeras muestras de una fase de desarrollo capitalista que para los mayores era inaudita y consoladora de la irrestricta miseria mientras que para ellos entraba en la órbita de lo ordinario y natural (Gracia y Ródenas 160-161).

El propio Ramón se incluye en el grupo de los «hijos de una educación, unos impedimentos, unos traumas que sólo se explicaban desde el franquismo» (Moix, Extraño 474). Ante esta certeza, a la crisis identitaria del autorreconocimiento se impone el tema generacional: «En unos ańos cruciales para la historia de mi país, el 
tema generacional se iba ampliando para convertirse, al fin, en una pregunta más rigurosa: ¿¿de dónde veníamos, qué proclamábamos, en qué consistía nuestra originalidad?» (473).

En esta línea Smith, en su análisis de El cine de los sábados, destaca la falta de compromiso moral de Moix con la historia y con la memoria (49) y añade que «he rejects the seductive mirage of a fixed identity only to replace it with a secondary, molecular narcissism. This prevents his text from addressing historical specificity, from confronting the inescapably political questions posed by homosexual identities» (52), lo que le aleja de poder ser considerado un autor comprometido con las reivindicaciones del colectivo gay en la época.

Sin embargo, en El beso de Peter Pan la continua recurrencia del cine representa para Ellis la relación entre cultura cinematográfica y autorrepresentación gay que puede interpretarse como una forma de responsabilidad hacia la memoria gay (citado por Ramos 85).

Por su parte, en Extraño en el paraíso varias son las ocasiones en las que las acciones colectivas, aparentemente banales, que se realizan en las fiestas organizadas por la comunidad gay de Barcelona, se ponen en perspectiva con las reivindicaciones que, en los setenta, mantuvo el movimiento gay. En primer lugar, estas acciones son valoradas como representaciones de "modelos finiseculares» (30) tendentes a desaparecer en pos del cosmopolitismo. De igual manera Moix valora la liberación sexual experimentada durante su estancia en Chelsea, cuyo principal atributo, la ambigüedad, juzga el autor que desaparecería con la llegada de movimientos como el Gay Power o el Women's Lib (324).

Precisamente a este respecto se pronuncia Mira, quien recela de la identificación de los autores españoles (Moix incluido) con las reivindicaciones del movimiento gay de los setenta por la limitación que ello suponía para los planteamientos estéticos de los escritores (De Sodoma 494). La práctica de la estética camp por gran parte de estos autores alejaba sus intereses del carácter social del movimiento (495), que entendía que estas propuestas culturales del camp tenían aspiraciones burguesas (487).

Como representante de esta estética, podemos aplicar a Moix en este punto las aseveraciones de Mira acerca de la utilidad de las manifestaciones camp para los homosexuales durante el franquismo. Según el crítico, su importancia se da en dos sentidos: por un lado, estas expresiones artísticas permitieron la búsqueda de referentes culturales en una época marcada por la marginalidad de la comunidad; por otro, son una influencia fundamental para el desarrollo de discursos propios que serán revisados, posteriormente, durante la Transición (343).

Estas vacilaciones, de las que daban cuenta los críticos en las citas anteriores, vienen a evidenciar una ambigüedad identitaria que permite interpretar la búsqueda de Moix. Su vacilación entre la pertenencia y el rechazo, entre la inclusividad y la exclusión, viene dada por la potencial proyección multidireccional de imágenes (cinematográficas, vivenciales, memorísticas) entre presente y pasado. Desde luego, el compromiso de Moix no es político, ni con el colectivo gay, ni con la generación de jóvenes. Se trata de un compromiso con la memoria, con la búsqueda de formas de autorrepresentación y expresión. Esta búsqueda, que parte, como ya hemos visto, 
de imágenes, permite la formulación de referentes colectivos que sirven, por un lado, a la comunidad gay, porque presenta modelos literarios y culturales, modelos de ser; por otro, a la generación de jóvenes adultos, porque establece una serie de referentes culturales que contribuyen a la construcción de la memoria colectiva del grupo.

Aparte de esta pertenencia a la comunidad que subyace a las obras de Moix y que hemos analizado anteriormente, es preciso estudiar de igual manera el compromiso de Moix con la memoria colectiva de su generación en sus textos memorialistas de Extraño en el paraíso.

En diferentes momentos del volumen, Ramón muestra su camaradería con migrantes con quienes compartió experiencia en París y Londres. De esta forma ocurre con la comuna de muchachos que se aloja precariamente en la librería Shakespeare and Company de París, de quienes se ofrece una imagen de jóvenes cultos con los que se comparte la miseria del trabajador migrante que sobrevive limpiando chimeneas en las casas pudientes parisinas.

Asimismo, esta camaradería está presente durante la estancia de Ramón en Chelsea, donde trabaja en un restaurante: «Más que en los días y sus trabajos nos fuimos aproximando en el culto a lo efímero. Las cancioncillas de los años cincuenta nos acercaron hasta alcanzar el nivel exacto de las confidencias» (306-307). Y también, un poco después, durante los meses que pasó en el pueblo de Plaxtol: «Entre bromas y bromas, resultó que mis relaciones con los demás camareros fueron óptimas. Una vez más eran compatriotas por partida doble: por España y por Sodoma» (425).

Las vivencias en el exterior le llevan a ser más consciente de su generación y son el germen de El día que murió Marilyn, rostro popular, el de la actriz, con el que su generación comenzaba a identificarse (471). Así se manifiesta un mayor discernimiento de los acontecimientos que estaban marcando a los jóvenes españoles de finales de la década de los sesenta. Moix se da cuenta de que, aún con el sonido de las canciones pop británicas en el oído, a su vuelta a España este se transforma en «las sirenas de la policía reprimiendo manifestaciones antifranquistas» (471), lo que le conduce a contemplar la significación política y «adscribirse a las tendencias más progresistas de su tiempo" (472). Pero este compromiso con su generación no se produce a través de su militancia política ${ }^{9}$, sino que, al igual que otros escritores de su época, se realiza a partir del tratamiento en sus escritos de una serie de elementos que tienen significancia memorística para la generación: imágenes cinematográficas, referencias a historietas, a personajes ficticios y reales, a espacios urbanos (Łuczak 123), etc. En definitiva, a un conjunto de elementos culturales comunes a su generación que contribuyen a la formalización de un discurso generacional y una memoria colectiva (Fone, Persona 190).

9 Pese a ello se ha defendido la actitud posnacionalista del escritor catalán (Ramos 98). 


\section{CONCLUSIÓN}

La obra memorialística de Terenci Moix constituye, sin lugar a dudas, una revisión del pasado personal que el escritor lleva a cabo durante su edad adulta. Aun así, el tratamiento que realiza de los recuerdos de infancia, adolescencia y juventud permite apreciar de qué manera no solo se fue configurando su singularidad identitaria a ojos de su protagonista, sino cómo la acumulación de un amplio conjunto de elementos de la cultura configura los intereses narrativos que están presentes en su obra novelística y ensayística.

En el tercer volumen de sus memorias (Extraño en el paraíso), Moix aborda el contenido de una época fundamental en el desarrollo del Ramón adulto y que resulta de máximo interés para entender cómo finaliza el proceso de formalización identitaria de la infancia hasta el acceso a la edad adulta y el despertar a un mundo exterior (incluso extranjero), ajeno al ambiente familiar y del barrio. Entre sus páginas se puede valorar cómo el escritor polemiza con su identidad gay, pero también con su compromiso con los movimientos sociales de la década de los sesenta.

Aunque, como se ha defendido, la estética camp colabora en la creación de un espacio de relación en la comunidad gay de su época, no es posible asegurar el compromiso de Moix con las reivindicaciones del movimiento gay que siguió al momento de estas memorias, en los años setenta. El escritor no hace suyas las reivindicaciones políticas del movimiento, a pesar de que es consciente de la evolución de determinadas prácticas de la década, como la ambigüedad sexual y el amor libre, en luchas más comprometidas con un cambio social.

No obstante, a la vista de la escritura del autor catalán, existe un compromiso cultural con la memoria de su generación. De manera que Moix toma elementos de su propia memoria, que incluyen por supuesto imágenes de la Espańa represiva, y los reelabora narrativamente, al mismo tiempo que los une con materias colectivas (como referencias al cine clásico de los años cuarenta, los cómics, lecturas, músicas y otros elementos de la cultura de masas), participa de un proceso de creación del relato que, lejos de la imagen solitaria y frívola que comúnmente se tiene, impulsa una consideración similar a la que otros escritores de la época mantuvieron, en lo que respecta al compromiso, desde un punto de vista cultural, con la memoria colectiva de la generación. 


\section{REFERENCIAS BIBLIOGRÁFICAS}

Dollimore, Jonathan. Sexual Dissidence: Augustine to Wilde, Freud to Foucault. Oxford: Oxford University Press, 1991.

Domínguez Santana, Fermín. «Marsé y las secciones de Por Favor. Una perspectiva en torno a su narrativa». Tesis doctoral. Universidad de La Laguna, 2011 (http://riull.ull.es/xmlui/ handle/915/3397).

Ellis, Robert Richmond. The Hispanic homograph: gay self-representation in contemporary Spanish autobiography. Illinois: University of Illinois Press, 1997.

Facultad de Filosofía y Letras. Ciclo «El intelectual y su memoria»: Terenci Moix. Entrevista en vídeo. Universidad de Granada. (https://www.youtube.com/watch?v=lkBILAAX3vk).

Fernàndez, Josep-Anton. Another Country: Sexuality and National Identity in Catalan Gay Fiction. Londres: Modern Humanities Research Association, 2000.

Fone, Thomas. «Ironía en la escritura memorialística de Terenci Moix (El cine de los sábados, El beso de Peter Pan y Extraño en el paraíso)», Epos XXVII (2011), pp. 131-144.

Fone, Thomas. «Persona y personaje en la escritura memorialística de Terenci Moix», Revista de Filología, 39 (2019), pp. 185-200.

GonzÁlez-Allende, Iker. "Onanismo y emigración gay en las memorias de Terenci Moix», en Godón, Nuria y Horswell, Michael J. (eds.), Sexualidades periféricas: Consolidaciones literarias y filmicas en la España de fin del siglo XIX y fin de milenio. Madrid: Fundamentos, 2016, pp. 183-208.

Gracia, Jordi y Ródenas, Domingo. Historia de la literatura española. 7. Derrota y restitución de la modernidad, 1939-2010. Barcelona: Crítica, 2011.

GuAsch, Oscar. La sociedad rosa. Barcelona: Anagrama, 1991.

GuAsch, Oscar. «La construcción cultural de la homosexualidad masculina en España (1970-1995)», en Mérida, Rafael M. (ed.), Minorías sexuales en España (1970-1995). Textos y representaciones. Barcelona: Icaria, 2013.

ŁUCZAK, Barbara. Espai i memòria: Barcelona en la novel.la catalana contemporània. Barcelona: Fundació Mercè Rodoreda, 2012.

Martínez Expósito, Alfredo. Los escribas furiosos: configuraciones homoeróticas en la narrativa espanola. New Orleans: University Press of the South, 1998.

Martínez Expósito, Alfredo. «Normalización y Teoría Queer», en Teoría Queer: de la transgresión a la transformación social. Andalucía: Fundación de Estudios Andaluces, 2009, pp. 24-38. https://www.centrodeestudiosandaluces.es/datos/factoriaideas/PN03_09.pdf.

Mira, Alberto. De Sodoma a Chueca. Una historia cultural de la homosexualidad en España en el siglo XX. Barcelona \& Madrid: Egales, 2004.

Mira, Alberto. «El niño queer en El peso de la paja de Terenci Moix», en Mérida Jiménez, Rafael M. (ed.), Masculinidades disidentes. Barcelona: Icaria, 2016, pp. 185-206.

Morx, Terenci. El cine de los sábados (Memorias. El Peso de la Paja 1). Barcelona: Planeta, 1998.

Morx, Terenci. Extraño en el paraíso (Memorias. El Peso de la Paja 3). Barcelona: Planeta, 1998.

Moret, Xavier. «Terenci Moix: 'He escrito mis memorias como si se tratara de una novela', El País. 15 diciembre 1993. (https://elpais.com/diario/1993/12/15/cultura/755910013_850215.html). 
Ramos, Carlos. «Terenci Moix. De la transición heróica a la seducción de masas», en Bou, Enric y Pittarello, Elide (eds.), (En)claves de la Transición. Una visión de los Novísimos. Prosa, poesia y ensayo. Madrid: Iberoamericana, 2009, pp. 79-101.

RTVE. Discurso Juan Marsé. Premio Cervantes 2008. Vídeo. Archivo Premios Cervantes. (https:// www.rtve.es/alacarta/videos/premios-cervantes-en-el-archivo-de-rtve/juan-marse-premio-cervantes-2008/486258/).

Soler, Marc. «Susan Sontag no concede la categoría de nuevo movimiento a la posmodernidad», $E l$ Pais. 28 junio 1984. (https://elpais.com/diario/1984/06/28/cultura/457221604_850215. html).

Sмiтh, Paul Julian. Laws of Desire: Questions of Homosexuality in Spanish Writing and Film. 19601990. Oxford: Clarendon Press, 1992.

VIlaseca, David. Queer Events: Post-deconstructive Subjectivities in Spanish Writing and Film, 1960s to 1990s. Liverpool: Liverpool University Press, 2010. 